\title{
Correlation of discharges of rostral ventrolateral medullary neurons with the low-frequency sympathetic rhythm in rats
}

\author{
Wan-Ting Tseng ${ }^{\mathrm{a}, 1}$, Ruei-Feng Chen ${ }^{\mathrm{a}, 1}$, Meng-Li Tsai ${ }^{\mathrm{b}}$, Chen-Tung Yen ${ }^{\mathrm{a}, *}$ \\ a Institute of Zoology and Department of Life Science, National Taiwan University, 1 Roosevelt Road, Section 4, Taipei 106, Taiwan \\ ${ }^{\mathrm{b}}$ Department of Biomechatronic Engineering, National Ilan University, Ilan, Taiwan
}

\section{A R T I C L E I N F O}

\section{Article history:}

Received 10 November 2008

Received in revised form 17 February 2009

Accepted 23 February 2009

\section{Keywords:}

Rostral ventrolateral medulla

Sympathetic nerve activity

Low-frequency rhythm

Baroreflex

Sympathetic rhythm

\begin{abstract}
A B S T R A C T
The rostral ventrolateral medulla (RVLM) is critically important in the generation of sympathetic activity. The purpose of this study was to investigate whether discharges of RVLM neurons contribute to low-frequency (LF) sympathetic rhythms. Blood pressure (BP), renal sympathetic nerve activity (SNA), and neuronal activity in the RVLM were simultaneously recorded in seven anesthetized, paralyzed, and artificially ventilated rats. Fifty-one RVLM neurons were recorded and classified into three differential functional groups according to their activities related to baroreceptor input. Those in the category of spike firing inhibited by a $\mathrm{BP}$ increase $\left(\mathrm{BP}^{\mathrm{I}}\right)$ and which excited sympathetic discharges was the most abundant (24\%). Coherence analysis was used to examine the relationship of the firing frequency of RVLM neurons with the LF $(0.2-0.8 \mathrm{~Hz})$ rhythm of SNA. Forty-one percent of RVLM neurons showed a significant correlation to LF rhythms, and BPI neurons with sympathoexcitatory properties were the major contributors. In another 4 baroreceptor-denervated rats, 36 RVLM neurons were recorded. In these rats, RVLM neuronal activities no longer changed with BP fluctuations. Nevertheless, more than $40 \%$ of RVLM neurons were sympathoexcitatory, and 36\% of RVLM neurons were still correlated with the LF SNA rhythm. Our results suggest that there are RVLM neurons involved in generating the LF rhythm in SNA and that the baroreflex can induce the participation of more neurons in LF rhythm generation.
\end{abstract}

(c) 2009 Elsevier Ireland Ltd. All rights reserved.
One of the most attractive features of the sympathetic nervous system is its rhythmicity. It has been well established that sympathetic nerve activity (SNA) contains various distinct rhythms [13,14]. In the case of conscious rats, Kunitake and Kannan [13] demonstrated that four frequency components occurred at $0.5,1.5,6$, and $12 \mathrm{~Hz}$ in SNA, corresponding to the low frequency (LF) of the heart rate (HR) and blood pressure (BP) variability, respiration, heart beat, and heart-beat harmonics, respectively. It is generally accepted that oscillations in SNA of $>1 \mathrm{~Hz}$ are dependant on reflexive regulation of respiration and the heart beat, but the origin of slow sympathetic rhythms below the respiratory frequency remains controversial.

Because spectral powers of LF rhythms of BP and SNA decrease after baroreceptor denervation, the baroreflex loop has been widely viewed as the predominant origin of the LF SNA rhythm $[3,4,11,13]$. The point is that in the baroreflex loop, the time constant of the sympathetic response to BP changes and that of sympathetic regulation of vascular smooth muscle are slow enough to generate LF fluctuations in SNA [15]. However, another view has also been put forward that central oscillators are responsible for generating the

\footnotetext{
* Corresponding author. Tel.: +8862 33662451; fax: +886223625048.

E-mail address: ctyen@ntu.edu.tw (C.-T. Yen).

1 These authors contributed equally to this work.
}

LF SNA rhythm. It was found that the slow SNA rhythm associated with the Mayer wave in cats persists after abolishing the baroreceptor afferent inflow [19]. This is also supported by findings that the slow SNA rhythm remains in spinal animals [16] and the existence of a pacemaker-like property of spinal neurons [21].

In studies searching brain regions critical for generating sympathetic periodicity, the rostral ventrolateral medulla (RVLM) deserves special attention. Neurons in the RVLM not only provide a tonic drive to SNA $[10,25]$, but also are crucial for the respective sympathetic fast periodicities of $1-6$ and $10 \mathrm{~Hz}$ in cats and rats $[1,2,8,23,27]$. Considering this evidence, it is possible that RVLM neurons play a role in generating LF sympathetic rhythms. Therefore, the purpose of this study was to investigate which types of RVLM neurons contribute to the LF SNA rhythm of rats. The neuronal activities of RVLM neurons, SNA, and BP were simultaneously recorded in intact and sinoaortic baroreceptor-denervated (SAD) rats. The responsiveness to BP elevation was used to classify RVLM neurons, and spike firing related to SNA was used to determine whether RVLM neurons have the capability to influence SNA. Coherence analysis was then used to correlate $\operatorname{LF}(0.2-0.8 \mathrm{~Hz})$ rhythms of SNA with the neuronal firing frequency.

Male Wistar rats (350-450 g) were anesthetized with a mixture of $\alpha$-chloralose $(60 \mathrm{mg} / \mathrm{kg})$ and urethane $(450 \mathrm{mg} / \mathrm{kg})$. The supplemental dose consisted of administration of a half dose of the 
mixture per kg intravenously. All animal care and experiment procedures performed in this study were approved by the Institutional Animal Care and Use Committee of National Taiwan University, and were in accordance with guidelines specified in the "Codes for Experimental Use of Animals" of the Council of Agriculture of Taiwan, based on the Animal Protection Law of Taiwan. The right femoral artery and veins of both sides were cannulated to measure BP and administer drugs, respectively. Rats were paralyzed (with gallamine triethiodide, $50 \mathrm{mg} / \mathrm{kg}$ i.v., initial dose) and artificially respired with room air. The end-tidal $\mathrm{CO}_{2}$ was kept within the range of 3.5-4.5\%, and the rectal temperature was kept at about $37 \pm 0.5^{\circ} \mathrm{C}$ with an electric blanket.

The left kidney was exposed, and the renal nerve was dissected free from the surrounding connective tissues and crushed distally. A bipolar hook electrode made of stainless steel microwires (biomedical wire AS 634, Cooner Wire; Chatsworth, CA) was positioned under the renal nerve. Both the exposed nerve and electrode were encased in silicon gel (Wacker Siligel 604; Munich, Germany).

Rats were mounted on a stereotaxic apparatus. A craniotomy was performed to expose the medulla. Michigan probes (linear probe, a1 × 16-5 mm 50-177, NeuroNexus Technologies, Ann Arbor, MI) were used to extracellularly record RVLM neurons (1-2 mm anterior to the obex, $1.6-2.4 \mathrm{~mm}$ lateral from the midline, and 2.8-3.1 mm ventral from the obex), the position of which was determined using an atlas [18]. To confirm the accuracy of the recording sites, a microwire was adhered to the tip of the Michigan probe (Fig. 1A) to produce a lesion ( $30 \mu \mathrm{A}, 10 \mathrm{~s}$, three times) in seven rats. In another four rats, AC current ( $20 \mu \mathrm{A}, 10 \mathrm{~s}$, three times) was used to produce a small lesion in the 16 th channel (deepest) of the Michigan probe.

Surgery to denervate the baroreflex followed the procedure of Barres et al. [5]. Briefly, the carotid sinus, superior laryngeal nerves, superior cervical ganglia, part of the sympathetic trunk behind the ganglia, aortic depressor, and cervical vagus nerves were sectioned bilaterally. After denervation, $3 \% \mathrm{H}_{2} \mathrm{O}_{2}$ was administered around the carotid artery to eliminate the neural activities of tiny nerves. The quality of denervation was tested with phenylephrine administration $(25 \mu \mathrm{g} / \mathrm{kg}$, as a bolus). If the HR decreased by $<10$ beats per minute (bpm) after more than a $20-\mathrm{mmHg}$ BP increase, denervation was confirmed [6]. BP, SNA, and neuronal activity of RVLM neurons were continuously recorded for $50 \mathrm{~min}$. The spontaneous activities of these three signals were recorded in the first $20 \mathrm{~min}$, and then phenylephrine $(12.5 \mu \mathrm{g} / \mathrm{kg} / \mathrm{min}$ ) was infused intravenously for $20 \mathrm{~min}$. After the infusion was completed, the recordings continued for an additional $10 \mathrm{~min}$. At the end of the experiment, hexamethonium chloride $(20 \mathrm{mg} / \mathrm{kg}$ ) was given to determine the baseline value of renal SNA. After completing the experiment, the animal was deeply anesthetized and perfused with saline followed by a $4 \%$ formalin solution. The tissue was frozen-sectioned into 100$\mu \mathrm{m}$ slices and processed by Nissl staining. Lesion and recording sites were observed (Fig. 1B) and reconstructed with a camera lucida.

The BP was measured by connecting the arterial catheter to a precalibrated pressure transducer (Gould P23 ID, Gould Instruments, Cleveland, $\mathrm{OH}$ ) coupled to an amplifier (Grass 7D, Grass Instrument, Quincy, MA). Renal SNA was amplified $(10,000 \times)$, band-pass filtered (30-3000 Hz; Grass P511), and integrated using an integrator with a 20-ms reset time. For offline analysis, the BP and integrated SNA signals were digitized at 1024 samples/s using an MP 100 A/D converter (BIOPAC System, Goleta, CA). Extracellular recordings were taken with a Multichannel Neuronal Acquisition Processor (MNAP) system (Plexon, Dallas, TX). Signals were amplified and band-pass filtered (400-8 kHz). Extracellular single-units were recorded in real time using time-voltage windows and a principle component-based template-matching algorithm (Sortclient, Plexon). Before analyzing the relationship between RVLM neuronal
(A)
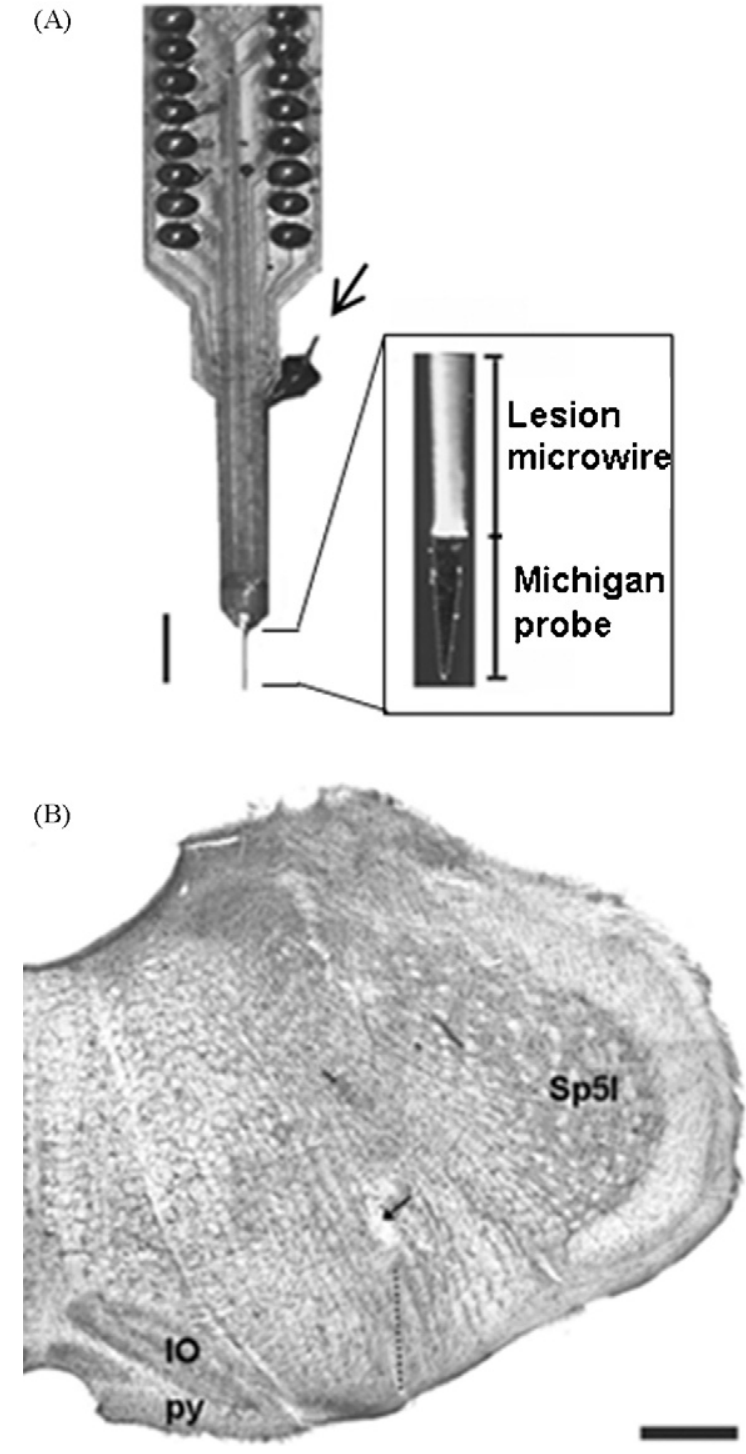

Fig. 1. (A) Modified Michigan probe with a microwire for producing a lesion (arrow); the inset on the right side is the tip of the electrode at a higher magnification. The arrow indicates the connector for the lesion. (B) Photomicrograph showing a lesion (arrow) and the estimated recording sites (dotted line below the lesion). Calibration lines in (A) and (B) are $5 \mathrm{~mm}$ and $500 \mu \mathrm{m}$, respectively. IO, inferior olive nucleus; Sp5I, spinal trigeminal nucleus, interpolar part; py, pyramidal tract.

firing and SNA, a cross-correlation computed by the NeuroExplorer software (Plexon) was used to remove other identical neurons recorded by adjacent channels lying on the Michigan probe.

A spike-triggered averaging analysis was carried out by the NeuroExplorer software (Plexon). At least 1000 spikes of single RVLM neurons were used as a reference to construct the average SNA. The $99 \%$ confidence limits calculated from averages in the period of $500 \mathrm{~ms}$ before spike firing were used as the criteria of correlation. If the averages exceed the upper or lower confidence limit, the RVLM neuron was defined as sympathetic excitatory or inhibitory property, respectively. If not, the RVLM neuron was defined as unrelated to the SNA. A dummy average was constructed from SNA triggered by artificial random spikes (with mean firing rate equal to the neuron contrasted) produced by a program computed in Matlab. The procedure of the spike-triggered averaging analysis in SAD rats was the same as above. Arterial pulse-triggered analysis was computed by the NeuroExplorer software with the value of systolic pressure of an arterial pulse as a reference. The pulse-triggered histograms of the firing pattern and simultaneously SNA were constructed. 
Table 1

Effect of phenylephrine infusion (PE) on the values of BP, SNA and HR.

\begin{tabular}{|c|c|c|c|c|c|c|}
\hline & \multicolumn{2}{|c|}{$\mathrm{BP}(\mathrm{mmHg})$} & \multicolumn{2}{|c|}{ SNA $(\mu \mathrm{Vs})$} & \multicolumn{2}{|l|}{$\mathrm{HR}$ (bpm) } \\
\hline & Control & $\mathrm{PE}$ & Control & PE & Control & $\mathrm{PE}$ \\
\hline Intact & $88 \pm 7$ & $116 \pm 5^{* *}$ & $44 \pm 17$ & $33 \pm 12^{*}$ & $428 \pm 17$ & $409 \pm 17^{*}$ \\
\hline SAD & $73 \pm 11$ & $89 \pm 15^{*}$ & $50 \pm 15$ & $47 \pm 14$ & $387 \pm 28$ & $385 \pm 29$ \\
\hline
\end{tabular}

Values are mean \pm S.E.M. BP, blood pressure; SNA, sympathetic nerve activity; HR, heart rate; SAD, sinoaortic baroreceptor-denervated rats.

* $p<0.05$ compared with the value before phenylephrine infusion.

** $p<0.01$ compared with the value before phenylephrine infusion.

The power spectra of SNA, neuronal activities of single RVLM neurons, and the corresponding coherence function were also calculated by NeuroExplorer. According to a previous study by Stauss et al. [22], we chose $0.2-0.8 \mathrm{~Hz}$ as the LF band. Fast Fourier transformation was performed on 46 non-overlapping contiguous 25.6-s windows of 20 min of spontaneous activity. The frequency resolution was $0.039 \mathrm{~Hz}$. Each spectrum was normalized as a percentage of the total power spectral density of $0-1 \mathrm{~Hz}$. According to a study by Barrès [3], the significance threshold $(p=0.01)$ for coherence was 0.09 .

The effect of phenylephrine infusion on physiological variables was analyzed by two-tailed paired $t$-test. The mean firing rate of the three groups of neurons was compared by the method of Kruskal-Wallis one-way ANOVA with Dunn's post hoc analysis. Significance was set at $p<0.05$. The results are expressed as mean \pm S.E.M.

The effect of phenylephrine infusion on the values of BP, SNA and HR were shown in Table 1 . In intact rats, the BP significantly increased by $28 \pm 4 \mathrm{mmHg}$, and the HR and SNA, respectively significant decreased by $19 \pm 7 \mathrm{bpm}$ and $11 \pm 5 \mu \mathrm{Vs}$ during the phenylephrine infusion. In 4 SAD rats, the BP significantly increased by $16 \pm 5 \mathrm{mmHg}$ during the phenylephrine infusion, but neither the HR nor SNA significantly changed.

Fifty-one neurons were recorded in the RVLM of seven intact rats. The recorded neurons were sorted into three types according to their responsiveness to raised $\mathrm{BP}$ (Fig. 2A), including $30 \mathrm{BP}-$ inhibited $\left(\mathrm{BP}^{\mathrm{I}}\right), 2 \mathrm{BP}$-excited $\left(\mathrm{BP}^{\mathrm{E}}\right)$, and $19 \mathrm{BP}$-non-responsive $\left(\mathrm{BP}^{\mathrm{N}}\right)$ neurons. The spontaneous firing rate of $\mathrm{BP}^{\mathrm{I}}$ neurons was significantly higher than that of $\mathrm{BP}^{\mathrm{N}}$ neurons (Fig. 3D top). Changes in the firing rate during raised $\mathrm{BP}$ were $-5.94 \pm 0.94 \mathrm{~Hz}$ for $\mathrm{BP}^{\mathrm{I}},+11.75 \mathrm{~Hz}$ for $\mathrm{BP}^{\mathrm{E}}$, and no significant change for $\mathrm{BP}^{\mathrm{N}}$ (Fig. 3D bottom). Rela- tionships between RVLM neuronal firing and SNA fluctuations in the time series were further evaluated by analyzing spike-trigger averages (Fig. 3A). In the $\mathrm{BP}^{\mathrm{I}}$ group, $40 \%, 30 \%$ and $30 \%$ of them had the capability to excite or inhibit, or were uncorrelated to SNA, respectively (Fig. 3C top). Neurons (53\%) uncorrelated to SNA were dominant in the $\mathrm{BP}^{\mathrm{N}}$ group (Fig. $3 \mathrm{C}$ top). Furthermore, in the analysis of arterial pulse-modulated SNA and neuronal activity, we found 94\% (16/17) sympathoexcitatory, 69\% (9/13) sympathoinhibitory and 48\% (10/21) SNA unrelated neurons have pulse-modulated activity (Fig. 3B).

Thirty-six RVLM neurons were recorded in four SAD rats. According to the same analytical methods, we found that the dominant population in SAD rats was $\mathrm{BP}^{\mathrm{N}}$ neurons (92\% of all RVLM neurons recorded in SAD rats), and $48 \%, 12 \%$, and $39 \%$ of $\mathrm{BP}^{\mathrm{N}}$ neurons had the capability to excite or inhibit or were uncorrelated to SNA, respectively (Fig. 3C bottom).

Coherence analysis was performed to determine the contribution of RVLM neurons to the LF SNA rhythm. An example of RVLM neuronal firing with or without a significant correlation to the LF SNA rhythm is shown in Fig. 4A. In intact rats, $41 \%$ of recorded neurons were significantly correlated with the LF SNA rhythm. These neurons were all in the $\mathrm{BP}^{\mathrm{I}}$ and $\mathrm{BP}^{\mathrm{N}}$ groups, and the dominant group was also $\mathrm{BP}^{\mathrm{I}}$-related neurons, especially $\mathrm{BP}^{\mathrm{I}}$ neurons with sympathoexcitatory capability (Fig. 4B top). The coherence values of $\mathrm{BP}^{\mathrm{I}}$ and $\mathrm{BP}^{\mathrm{N}}$ groups were $0.13 \pm 0.01$ and $0.12 \pm 0.01$ in LF range, respectively. Also, 36\% of RVLM neurons were significantly correlated to the LF SNA rhythm in SAD rats, but $\mathrm{BP}^{\mathrm{N}}$ neurons with sympathoexcitatory capability were dominant (Fig. 4B bottom).

In this investigation, functional groups of RVLM neurons and their relationship with SNA were classified according to the properties of their baroreceptor input and SNA output. BPI neurons with
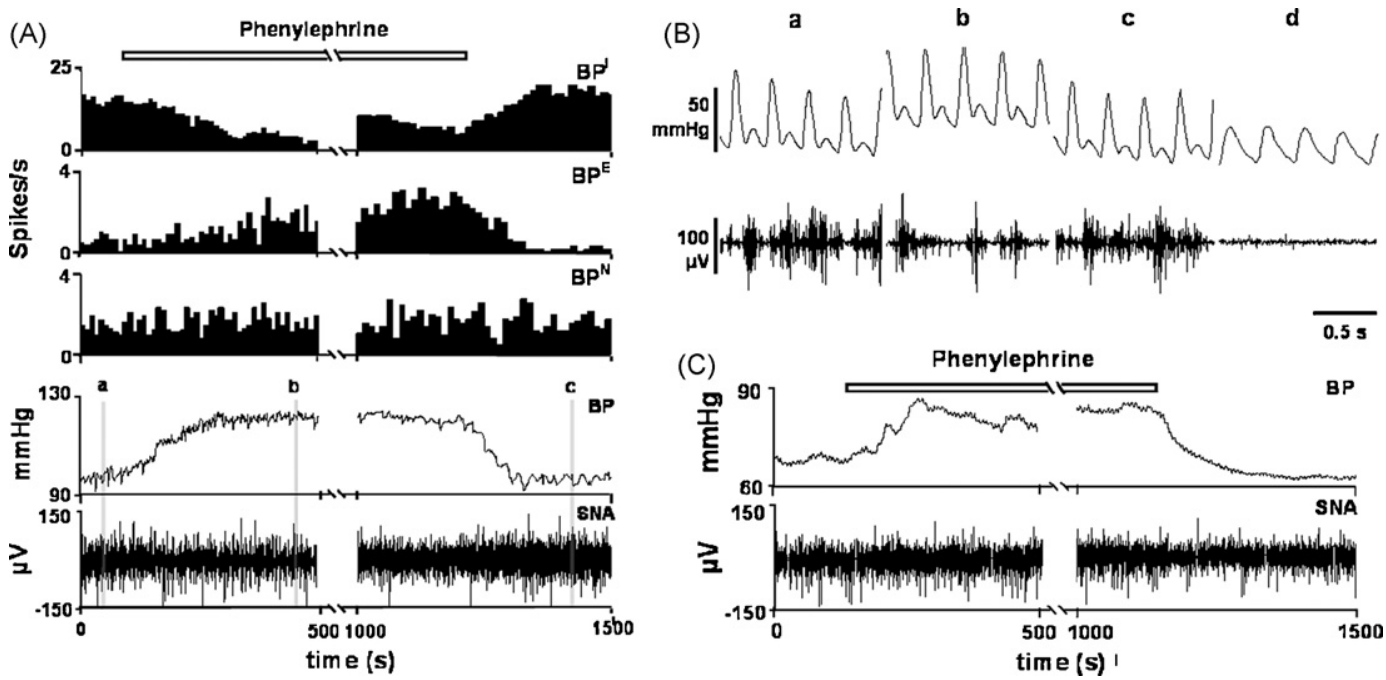

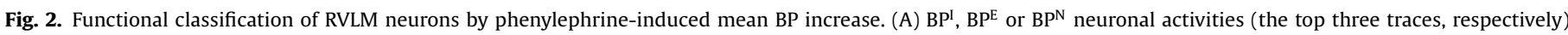

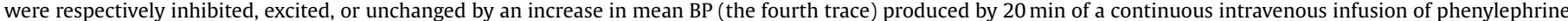

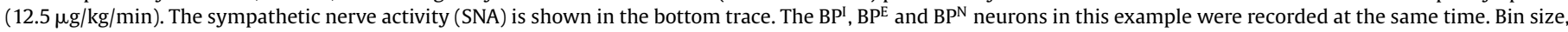

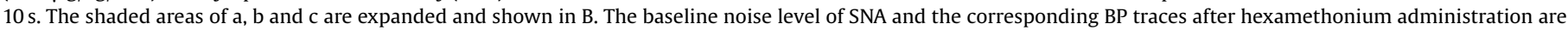
shown in Bd. (C) An example of mean BP increase under phenylephrine infusion in SAD rat. Notice the SNA was not changed significantly. 

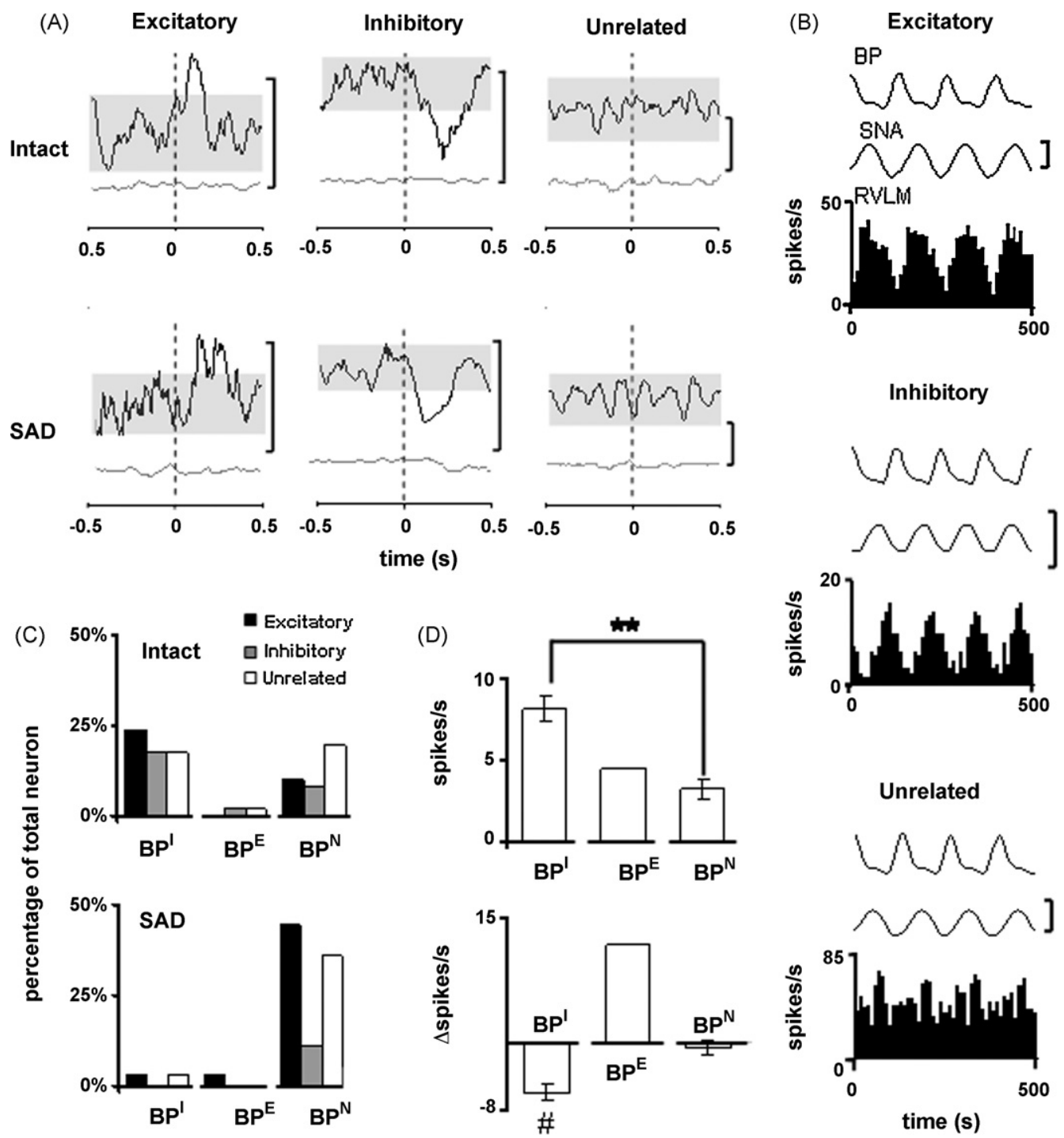

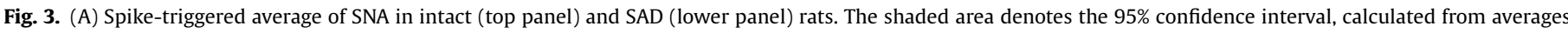

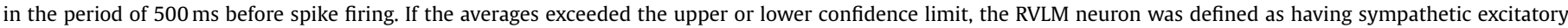

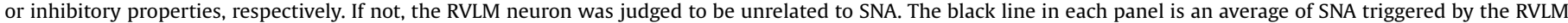

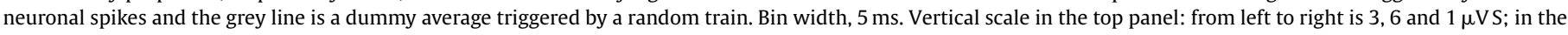

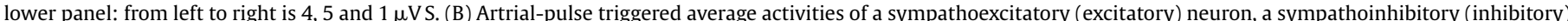

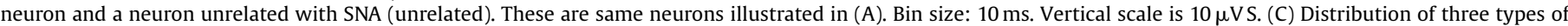

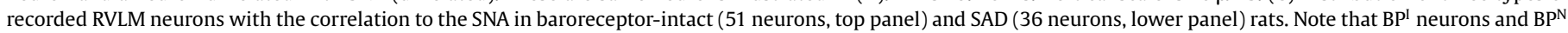

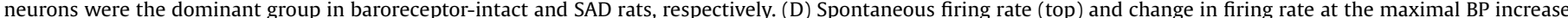

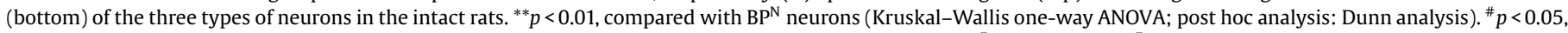

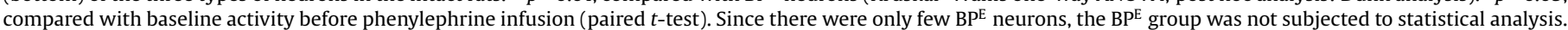

sympathoexcitatory properties were found to be the major contributor to the LF SNA rhythm in intact rats. After removing the baroreceptor input, some of the sympathoexcitatory neurons in SAD rats were still correlated to the LF SNA rhythm. These results suggest that vasomotor RVLM neurons contribute to the existence of the LF SNA rhythm.

The 16-channel Michigan probe could simultaneously record many single units in the RVLM. Accordingly, a more-balanced and unbiased sampling was obtained. Previously, many vasomotor sympathoexcitatory and baroreceptor inhibited neurons were found in the RVLM $[7,26]$. Our $\mathrm{BP}^{\mathrm{I}}$ neurons with pulse-modulation and sympathoexcitation capability had the same properties as these vasomotor neurons. When baroreceptors were removed from SAD rats, as expected, most RVLM neurons were unresponsive to a BP increase. On the other hand, the output of RVLM neurons remained intact as demonstrated by the many sympathoexcitatory neurons found in the BPN category. Thus, the data obtained in the present study provide a quantitative estimation of vasomotor neurons of $25-40 \%$ of the total RVLM population.

Eighteen percent (9/51) of RVLM neurons were BPI neurons with sympathoinhibitory properties and which were barosensitive, but the function was opposite to SNA regulation by the baroreflex. The mean lag of spike triggered averages for these neurons $(184.4 \pm 32.9 \mathrm{~ms})$ was significantly longer than that of $\mathrm{BP}^{\mathrm{I}}$ neurons with sympathoexcitatory capabilities $(93.3 \pm 18.0 \mathrm{~ms})$, which implies that inhibition of SNA is indirect and might occur through several layers of interneuron. In total, 18\% (9/51) of unrelated sympathetic neurons were found in the RVLM. These neurons might be interneurons the output projections of which go to locations other than the sympathetic trunk $[9,24]$.

The major hypothesis for the origin of LF SNA rhythms is synchronization of the baroreflex as suggested by evidence of the synchronization disappearing following opening of the baroreflex closed-loop $[3,4,11,13]$. However, in most such studies, the LF com- 

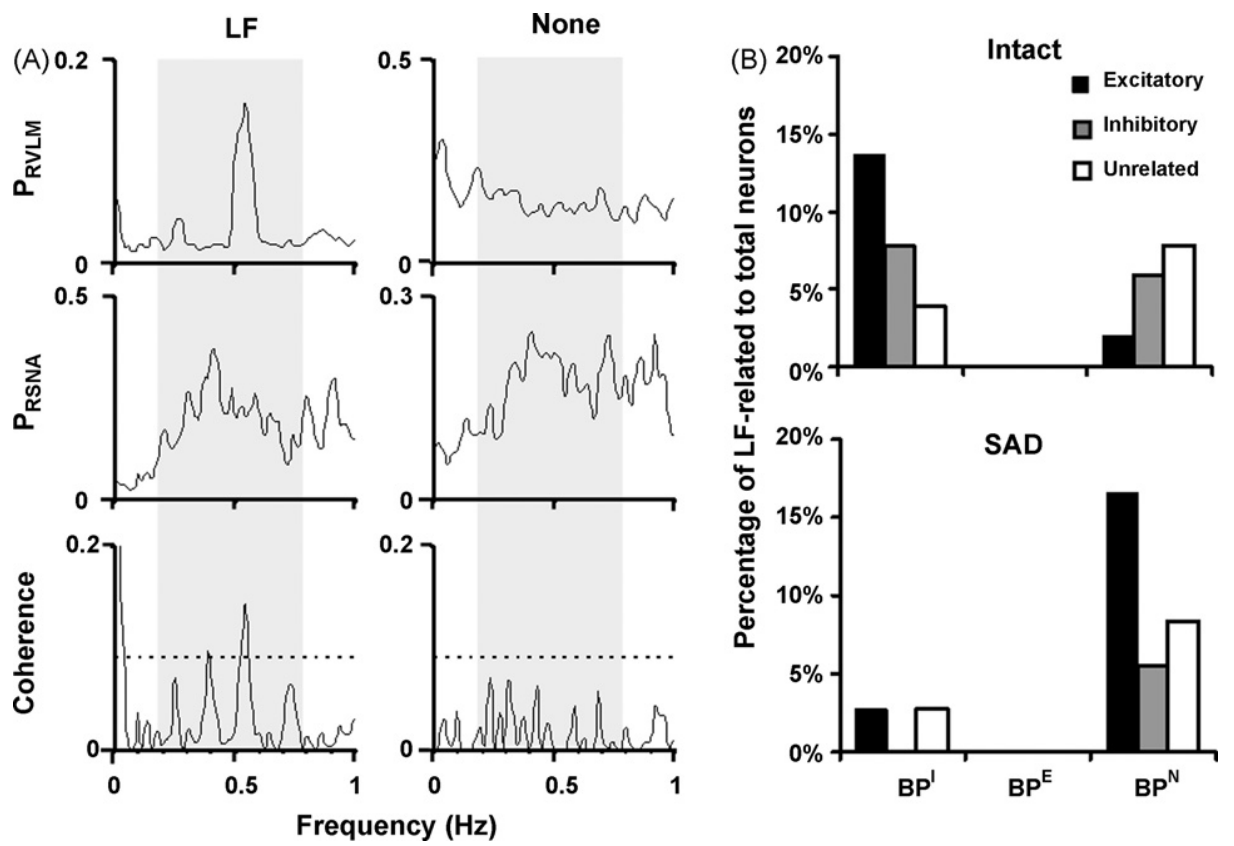

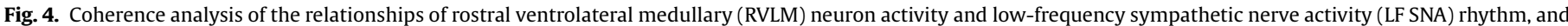

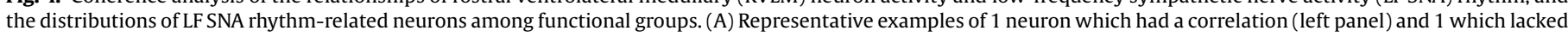

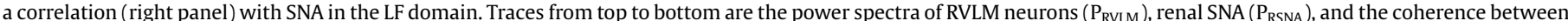

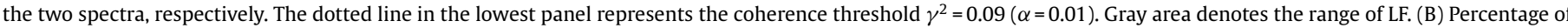

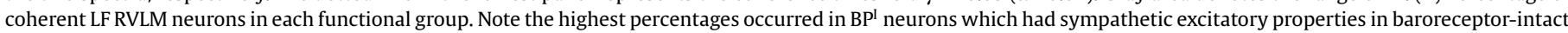
rats, and in $\mathrm{BP}^{\mathrm{N}}$ ones which had sympathetic excitatory properties in sinoaortic baroreceptor-denervated (SAD) rat.

ponent of SNA was only reduced but did not totally disappear after removing the baroreceptors [3,4,11], even after blockading the vascular neuroeffector junction [4]. Therefore, other sources for the LF component of SNA should exist. It has been proposed that the spinal cord is one of the origin sources. For example, the decerebratedvegotomized spinal cats still have LF and HF component in SNA [16], however, in the spinal cord transected rat, the slow rhythm at $0.4 \mathrm{~Hz}$ disappeared [20]. Furthermore, the slow rhythm of BP and SNA in spinalized and vagotomized dog were stronger following raised subarachnoid pressure [12]. In addition to the neurons in the spinal cord, the medullary neurons, including RVLM neurons, have been considered as the origin of the LF rhythms. After transecting the sinoaortic and vagal nerves, the medullary neurons still had high correlation with BP at LF rhythms [17].

In the present study, 62\% of RVLM neurons which contributed to LF rhythms were in the $\mathrm{BP}^{\mathrm{I}}$-related (i.e., barosensitive) group, and almost half were $\mathrm{BP}$ I neurons with sympathoexcitatory properties. This agrees well with results of the above-mentioned studies, that the baroreflex is involved in generating the LF SNA rhythm. However, the ratios of RVLM neurons which contribute to LF rhythms did not significantly differ between intact (41\%) and SAD rats (36\%). This supports the results in a cat study which found that the correlation between medullary neurons and BP at LF rhythms $(0.12 \pm 0.02 \mathrm{~Hz})$ remained after sectioning of the sinoaortic and vagal nerves [17]. Combining these two phenomena, RVLM neurons have the capability to generate the LF rhythm in SNA, and then to generate the LF rhythm in BP.

\section{Acknowledgements}

We thank Dr. Yen Chien-Chang (Department of Mathematics, Fu-Jen Catholic University, Taiwan) for his programming support with dummy strain generation. This study was supported by grants (NSC94-2314-B-197-001 and NSC94-2311-B002-022) from the National Science Council, Taiwan.

\section{References}

[1] S.M. Barman, G.L. Gebber, Rostral ventrolateral medullary and caudal medullary raphe neurons with activity correlated to the $10-\mathrm{Hz}$ rhythm in sympathetic nerve discharge, J. Neurophysiol. 68 (1992) 1535-1547.

[2] S.M. Barman, G.L. Gebber, Sympathetic nerve rhythm of brain stem origin, Am. J. Physiol. 239 (1980) R42-47.

[3] C. Barres, Y. Cheng, C. Julien, Steady-state and dynamic responses of renal sympathetic nerve activity to air-jet stress in sinoaortic denervated rats, Hypertension 43 (2004) 629-635.

[4] C. Barres, E.P. de Souza Neto, C. Julien, Effect of alpha-adrenoceptor blockade on the $0.4 \mathrm{~Hz}$ sympathetic rhythm in conscious rats, Clin. Exp. Pharmacol. Physiol. 28 (2001) 983-985.

[5] C. Barres, S.J. Lewis, H.J. Jacob, M.J. Brody, Arterial pressure lability and renal sympathetic nerve activity are dissociated in SAD rats, Am. J. Physiol. 263 (1992) R639-646.

[6] C.J. Barrett, S.J. Guild, R. Ramchandra, S.C. Malpas, Baroreceptor denervation prevents sympathoinhibition during angiotensin II-induced hypertension, Hypertension 46 (2005) 168-172.

[7] J.H. Coote, Landmarks in understanding the central nervous control of the cardiovascular system, Exp. Physiol. 92 (2007) 3-18.

[8] G.L. Gebber, S.M. Barman, M. Zviman, Sympathetic activity remains synchronized in presence of a glutamate antagonist, Am. J. Physiol. 256 (1989) R722-732.

[9] P.G. Guyenet, A.M. Schreihofer, R.L. Stornetta, Regulation of sympathetic tone and arterial pressure by the rostral ventrolateral medulla after depletion of C1 cells in rats, Ann. N.Y. Acad. Sci. 940 (2001) 259-269.

[10] A.S. Jansen, X.V. Nguyen, V. Karpitskiy, T.C. Mettenleiter, A.D. Loewy, Central command neurons of the sympathetic nervous system: basis of the fight-orflight response, Science 270 (1995) 644-646.

[11] C. Julien, B. Chapuis, Y. Cheng, C. Barres, Dynamic interactions between arteria pressure and sympathetic nerve activity: role of arterial baroreceptors, Am. J. Physiol. Regul. Integr. Comp. Physiol. 285 (2003) R834-841.

[12] R.J. Kaminski, G.A. Meyer, D.L. Winter, Sympathetic unit activity associated with Mayer waves in the spinal dog, Am. J. Physiol. 219 (1970) 1768-1771.

[13] T. Kunitake, H. Kannan, Discharge pattern of renal sympathetic nerve activity in the conscious rat: spectral analysis of integrated activity, J. Neurophysiol. 84 (2000) 2859-2867.

[14] S.C. Malpas, The rhythmicity of sympathetic nerve activity, Prog. Neurobiol. 56 (1998) 65-96

[15] S.C. Malpas, B.L. Leonard, S.J. Guild, J.V. Ringwood, M. Navakatikyan, P.C Austin, G.A. Head, D.E. Burgess, The sympathetic nervous system's role in regulating blood pressure variability, IEEE Eng. Med. Biol. Mag. 20 (2001) 17-24.

[16] N. Montano, C. Cogliati, V.J. da Silva, T. Gnecchi-Ruscone, M. Massimini, A. Porta, A. Malliani, Effects of spinal section and of positive-feedback excita- 
tory reflex on sympathetic and heart rate variability, Hypertension 36 (2000) 1029-1034.

[17] N. Montano, T. Gnecchi-Ruscone, A. Porta, F. Lombardi, A. Malliani, S.M. Barman, Presence of vasomotor and respiratory rhythms in the discharge of single medullary neurons involved in the regulation of cardiovascular system, J. Auton. Nerv. Syst. 57 (1996) 116-122.

[18] G. Paxinos, C. Watson, The Rat Brain in Stereotaxic Coordinates, 4th ed., Academic Press, New York, 1998.

[19] G. Preiss, C. Polosa, Patterns of sympathetic neuron activity associated with Mayer waves, Am. J. Physiol. 226 (1974) 724-730.

[20] D.C. Randall, B.R. Baldridge, E.E. Zimmerman, J.J. Carroll, R.O. Speakman, D.R Brown, R.F. Taylor, A. Patwardhan, D.E. Burgess, Blood pressure power within frequency range approximately $0.4 \mathrm{~Hz}$ in rat conforms to self-similar scaling following spinal cord transection, Am. J. Physiol. Regul. Integr. Comp. Physiol. 288 (2005) R737-741.

[21] D. Spanswick, S.D. Logan, Spontaneous rhythmic activity in the intermediolateral cell nucleus of the neonate rat thoracolumbar spinal cord in vitro, Neuroscience 39 (1990) 395-403.
[22] H.M. Stauss, R. Mrowka, B. Nafz, A. Patzak, T. Unger, P.B. Persson, Does low frequency power of arterial blood pressure reflect sympathetic tone? J. Auton. Nerv. Syst. 54 (1995) 145-154.

[23] R.D. Stein, L.C. Weaver, C.P. Yardley, Ventrolateral medullary neurones: effects on magnitude and rhythm of discharge of mesenteric and renal nerves in cats, J. Physiol. 408 (1989) 571-586.

[24] R.L. Stornetta, P.J. Akey, P.G. Guyenet, Location and electrophysiological characterization of rostral medullary adrenergic neurons that contain neuropeptide Y mRNA in rat medulla, J. Comp. Neurol. 415 (1999) 482-500.

[25] A.F. Sved, G. Cano, J.P. Card, Neuroanatomical specificity of the circuits controlling sympathetic outflow to different targets, Clin. Exp. Pharmacol. Physiol. 28 (2001) 115-119.

[26] A.F. Sved, S. Ito, C.J. Madden, S.D. Stocker, Y. Yajima, Excitatory inputs to the RVLM in the context of the baroreceptor reflex, Ann. N.Y. Acad. Sci. 940 (2001) 247-258.

[27] A. Trzebski, S. Baradziej, Role of the rostral ventrolateral medulla in the generation of synchronized sympathetic rhythmicities in the rat, J. Auton. Nerv. Syst. 41 (1992) 129-139. 